\title{
Evaluation of Silicon Phthalocyanine 4 Photodynamic Therapy against Human Cervical Cancer Cells in Vitro and in Mice
}

\author{
Jill A. Gadzinski', Jianxia Guo², Brian J. Philips', Per Basse3, Ethan K. Craig2,4, Lisa Bailey³, \\ Joseph Latoche ${ }^{5}$, John T. Comerci ${ }^{1}$, Julie L. Eiseman ${ }^{2 *}$
}

${ }^{1}$ Department of Obstetrics/Gynecology/Reproductive Sciences, Magee Women's Hospital of the University of Pittsburgh, Pittsburgh, PA, USA

${ }^{2}$ Cancer Therapeutics Program, University of Pittsburgh Cancer Institute, and Department of Pharmacology and Chemical Biology, School of Medicine, University of Pittsburgh, Pittsburgh, PA, USA

${ }^{3}$ Cancer Immunology Program, University of Pittsburgh Cancer Institute, and Department of Immunology, School of Medicine,

University of Pittsburgh, Pittsburgh, PA, USA

${ }^{4}$ School of Medicine, University of Pittsburgh, Pittsburgh, PA, USA

${ }^{5}$ Department of Cardiology, Molecular Imaging Center, University of Pittsburgh School of Medicine, Pittsburgh, PA, USA

Email: gadzinskija@upmc.edu, guoxjx@upmc.edu,philipsb@upmc.edu, basse@pitt.edu, Craig.Ethan@medstudent.pitt.edu, baillm2@upmc.edu, jd110@pitt.edu, comercijt@upmc.edu, *eisemanj@msx.upmc.edu

How to cite this paper: Gadzinski, J.A., Guo, J.X., Philips, B.J., Basse, P., Craig, E.K., Bailey, L., Latoche, J., Comerci, J.T. and Eiseman, J.L. (2016) Evaluation of Silicon Phthalocyanine 4 Photodynamic Therapy against Human Cervical Cancer Cells in Vitro and in Mice. Advances in Biological Chemistry, 6, 193-215.

http://dx.doi.org/10.4236/abc.2016.66017

Received: December 15, 2016

Accepted: December 27, 2016

Published: December 30, 2016

Copyright (๑) 2016 by authors and Scientific Research Publishing Inc. This work is licensed under the Creative Commons Attribution International License (CC BY 4.0).

http://creativecommons.org/licenses/by/4.0/

(c) (i) Open Access

\section{Abstract}

Background: Cervical cancer is the second most common cancer in women worldwide [1]. Photodynamic therapy has been used for cervical intraepithelial neoplasia with good responses, but few studies have used newer phototherapeutics. We evaluated the effectiveness of photodynamic therapy using Pc 4 in vitro and in vivo against human cervical cancer cells. Methods: CaSki and ME-180 cancer cells were grown as monolayers and spheroids. Cell growth and cytotoxicity were measured using a methylthiazol tetrazolium assay. Pc 4 cellular uptake and intracellular distribution were determined. For in vitro Pc 4 photodynamic therapy, cells were irradiated at $667 \mathrm{~nm}$ at a fluence of $2.5 \mathrm{~J} / \mathrm{cm}^{2}$ at $48 \mathrm{~h}$. SCID mice were implanted with CaSki and ME-180 cells both subcutaneously and intracervically. Forty-eight hours after Pc 4 photodynamic therapy was administered at 75 and $150 \mathrm{~J} / \mathrm{cm}^{2}$. Results: The $\mathrm{IC}_{50}$ s for Pc 4 and Pc 4 photodynamic therapy for CaSki and ME-180 cells as monolayers were, $7.6 \mu \mathrm{M}$ and $0.016 \mu \mathrm{M}$ and $>10 \mu \mathrm{M}$ and $0.026 \mu \mathrm{M}$; as spheroids, $\mathrm{IC}_{50} \mathrm{~s}$ of Pc 4 photodynamic therapy were, $0.26 \mu \mathrm{M}$ and $0.01 \mu \mathrm{M}$. Pc 4 was taken up within cells and widely distributed in tumors and tissues. Intracervical photodynamic therapy resulted in tumor death, however mice died due to gastrointestinal toxicity. Photodynamic therapy resulted in subcutaneous tumor death and growth delay. 
Conclusions: Pc 4 photodynamic therapy caused death within cervical cancer cells and xenografts, supporting development of Pc 4 photodynamic therapy for treatment of cervical cancer. Support: P30-CA47904, CTSI BaCCoR Pilot Program.

\section{Keywords}

Cervical Cancer, Lasers, Silicon Phthalocyanine 4, Photodynamic Therapy

\section{Introduction}

Cervical cancer is the second most common cancer in women worldwide behind breast cancer [1]. In developing countries, cervical cancer is the most common cancer in women and the leading cause of cancer death [2]. In the United States, according to the American Cancer Society, there will be approximately 12,900 new cases and 4100 deaths in 2015 [3]. Cervical cancer can be categorized by extent of the spread of disease: localized tumors up to $4 \mathrm{~cm}$ are early stage disease; tumors larger than $4 \mathrm{~cm}$ or with paracervical involvement are locally advanced disease; involvement of other pelvic organs or distant metastases is advanced disease [4]. In the United States and Canada, concomitant chemoradiation is the standard of care for locally advanced disease and advanced disease, while neoadjuvant chemotherapy followed by radical surgery is used in Europe, Asia and Latin America [4]. Treatment of locally advanced disease with concomitant chemoradiation is often suboptimal and leaves approximately $40 \%$ of patients with residual disease [5]. There are limitations on the total radiation dose that can be administered so patients with persistent or recurrent disease after chemoradiation have few therapeutic options other than radical pelvic surgery that often entails removal of the rectum, bladder and vagina en bloc.

For cervical intraepithelial neoplasia (CIN), a preinvasive disease, the treatment is excisional or ablative therapy: LEEP (loop electrosurgical excision procedure), CKC (cold knife conization) or local destruction with either $\mathrm{CO}_{2}$ laser or cryotherapy [6]. These excisional and ablative treatments can negatively impact the reproductive health of the women by potentially increasing the risk of preterm premature rupture of membranes and preterm labor [7] [8] [9]. There has been little progress in the last 20 years examining novel therapeutic modalities for CIN or cervical cancer.

Photodynamic therapy (PDT) is an attractive treatment modality for both preinvasive disease and invasive cervical cancer because its therapeutic agents, a photosensitizer, light and oxygen, are safe by themselves but lead to selective tumor destruction when combined. Advantages of PDT in the treatment of CIN and invasive cervical cancer include: the ability to localize treatment with the application of light; the sparing of intracellular matrix allowing regeneration of normal tissue; the potential for repetition of therapy without accumulation of toxicity; the potential of combining PDT with chemotherapy and, or radiation therapy to improve their efficacies; and the enhancement of antitumor immunity which may contribute to long term tumor control [8] [9]. Finally, PDT does not require anesthesia and generally does not cause bleeding which 
makes its use applicable to the outpatient setting.

The most widely used PDT therapeutics are Photofrin and various forms of 5-amino levulinic acid (ALA). Most recently, topical formulations of ALA have been used directly in the cervix with remission rates of $71 \%, 50 \%$ and $71 \%$ for CIN 1,2 and 3 [8]. To date, PDT has not been used in the treatment of invasive cervical cancer.

Silicon phthalocyanine 4 ( $\mathrm{Pc} 4$ ) (Figure 1) is a second generation photosensitizer developed at Case Western Reserve University in coordination with the Drug Decision Network of the National Cancer Institute. Among Pc 4's desirable features are: its chemical purity; its high extinction coefficient, $0.23 \mathrm{~cm}^{-1} \mu \mathrm{M}^{-1}$ at $670 \mathrm{~nm}$ in aqueous solution, a wavelength allowing deep tissue penetration of light; and its rapid clearance from skin which limits the extent and duration of cutaneous photosensitivity after intravenous administration [10] [11] [12]. Pc 4 accumulates in the mitochondria, lysosomes and endoplasmic reticulum of the cells and Pc 4 PDT results in the generation of reactive oxygen species that result in both apoptosis and necrosis of cells exposed to PDT. This effect of Pc 4 PDT has been demonstrated in numerous studies of cells in vitro [13] [14] [15]. Pc 4 PDT has also demonstrated promise in preclinical studies of

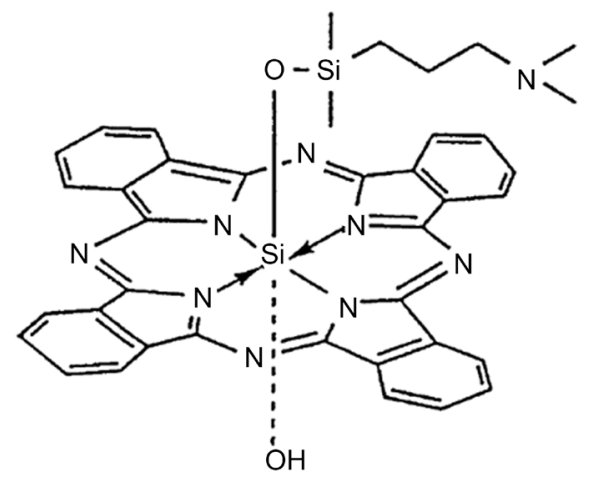

(a)

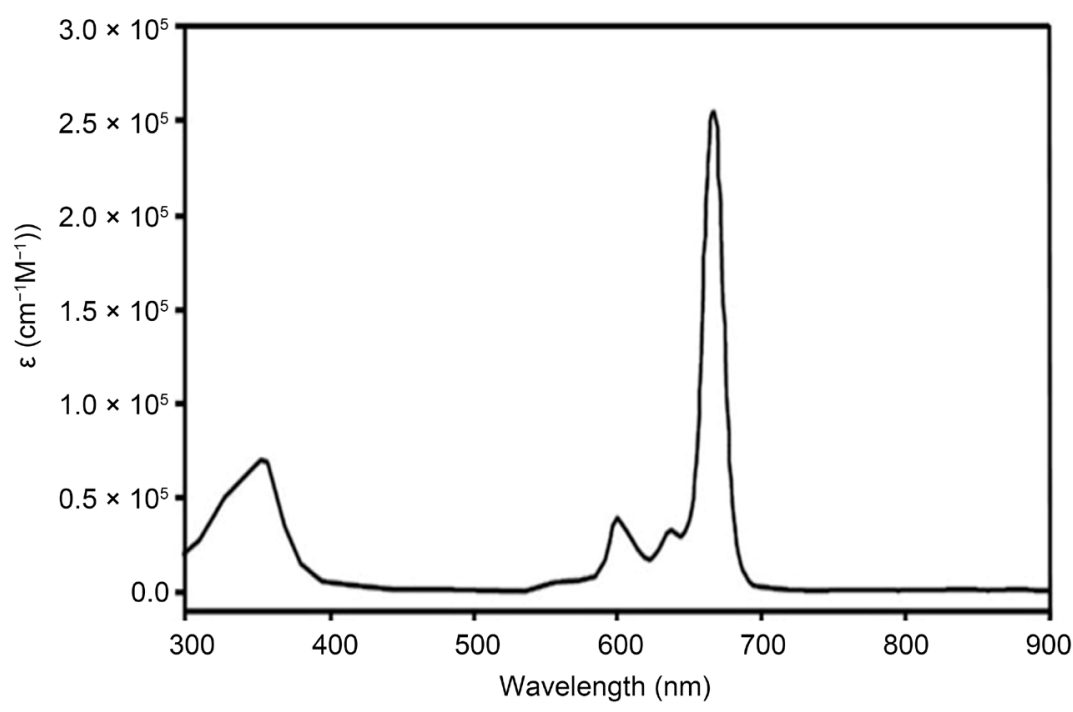

(b)

Figure 1. Structure and absorbance spectra of Pc 4 in $1 \times$ phosphate buffered saline. 
squamous cell cancers of the head and neck, and has been used topically to treat cutaneous t-cell leukemia [14] [16]. In spite of its effectiveness and good safety profile in the Phase I clinical trial in cutaneous t-cell leukemia [16], Pc 4 has not been evaluated in further clinical trials to date.

In this study, we evaluated the effectiveness of Pc 4 PDT in inhibiting the growth of human cervical cancer cells in vitro when grown as monolayers and spheroids, and in vivo. We measured the uptake of Pc 4 by the cells over time and the Pc 4 intracellular localization. We also examined the growth of cervical cancer cells when implanted in the cervix of immunodeficient mice and the uptake of Pc 4 by cervical cancer xenografts as well as other tissues after IV administration of Pc 4. We attempted intravaginal and subcutaneous delivery of irradiation after treatment of the mice with Pc 4. This preliminary data will be used to support further in vivo studies of Pc 4 PDT in the treatment of CIN and cervical cancer.

\section{Materials and Methods}

\subsection{Materials}

Pc 4 (NSC 676418) was obtained from the Cancer Treatment Evaluation Program of the National Cancer Institute (Bethesda, MD). Sterile water and $0.9 \%$ sodium chloride injection solution (saline) were purchased from Baxter Healthcare Corp (Deerfield, IL). RPMI medium, fetal bovine serum, trypsin-EDTA (10×), penicillin-(100 U) streptomycin $\mu \mathrm{g} / \mathrm{ml}$ in $0.85 \%$ saline and PBS ( $\mathrm{pH} 7.4$, without calcium or magnesium) were purchased from Invitrogen (Carlsbad, CA). Intralipid 10\% IV fat emulsion was purchased from Fresenius Kabi Clayton, L.P. (Clayton, NC). Cremophor El, dimethyl sulfoxide, microtetrazolium dye (MTT, 3-(4,5-dimethylthiazol-2-yl)-2,5-diphenyltetrazolium bromide) and nile blue were purchased from Sigma Aldrich Corp (St. Louis, MO). Ethanol was purchased from Pharmco Products, Inc. (Brookfield, CT). HPLC grade ethyl acetate and glacial acetic acid were purchased from J. T. Baker (Phillipsburg, NJ). HPLC grade methanol was purchased from Fisher Scientific (Pittsburgh, PA). Nembutal and Buprenex (Buprenorphine) were purchased from Henry Schein Animal Health, Inc. (Melville, NY), isoflurane from Hospira, Inc. (Lake Forest, IL) and heparin sodium for injection (10,000 U mL) was purchased from American Pharmaceutical Partners, Inc. (Schaumburg, IL).

\subsection{Cell Culture}

The human squamous cell carcinomas of the uterine cervix, CaSki and ME-180, were obtained from the American Type Culture Collection (CaSki:ATCC ${ }^{\oplus}$ CRL- $1550^{\text {tw }}$ and ME-180:ATCC ${ }^{\oplus}$ HTB-33 $^{\text {tw }}$, Manassas, VA) and cultured in RPMI 1640 medium (Fisher Scientific) with L-glutamine, containing $10 \%$ fetal bovine serum, penicillin (100IU), streptomycin $(100 \mu \mathrm{g} / \mathrm{mL})$ and maintained in an incubator at $37^{\circ} \mathrm{C}, 5 \% \mathrm{CO}_{2}$ and $95 \%$ humidity. Monolayers were grown in standard 96-well flat bottom plates. Spheroids were created using Perfecta3 $\mathrm{D}^{\circ}$ Hanging Drop Plates (3D Biomatrix, Ann Arbor, MI) and were cultured on Corning ${ }^{\mathrm{Tx}}$ Matrigel $^{\mathrm{Tm}}$ Membrane Matrix (Fisher Scientific) 1:1 with 
complete media.

\subsection{Prevention of Phototoxicity}

In order to prevent phototoxicity due to room lighting, cells removed from the incubator were processed in a vented laminar flow hood without lights and surrounded by green theatrical gels (Lee filter, 124) prior to and after introduction of Pc 4. Similarly, mice were housed in cages surrounded by these same theatrical gels 1 week following the administration of Pc 4 to prevent skin phototoxicity.

\subsection{PDT in Vitro}

Cells in logarithmic growth, $24 \mathrm{~h}$ after the addition of Pc 4, were irradiated through a microlens diffuser fiber (P/N5470RevD; 40 micron core, Pioneer Optics Co., Bloomfield, CT) on a diode laser (HPD $670 \mathrm{~nm}$ laser, 7404-D-EXT; High Power Devices, Inc., New Brunswick, NJ) at $670 \mathrm{nM}$. The laser was calibrated using a power meter (PM100; Thorlabs, Newton, NJ). Fluence was maintained at $2.5 \mathrm{~J} / \mathrm{cm}^{2}$ because it was the most effective over a wide range of Pc 4 concentrations in monolayers than fluences of 0.1 , 0.2 , and $1 \mathrm{~J} / \mathrm{cm}^{2}$ (our unpublished data; to vary the fluence, time was adjusted as power was constant). To maintain fluence of $2.5 \mathrm{~J} / \mathrm{cm}^{2}$ between experiments, we varied time based on power as detected by the power meter $\left(t=\right.$ Fluence $\times\left(\pi \times\right.$ radius $\left.^{2}\right) /$ Power $)$ and was approximately $24 \mathrm{~min}$ to irradiate a 96 -well plate from above within a circle with a diameter of $12 \mathrm{~cm}$ with an median power of $190 \mathrm{~mW}$.

\subsection{Cytotoxicity of Pc 4 and Pc 4 PDT in Cell Monolayers}

CaSki cells or ME-180 cells $\left(1 \times 10^{5}\right.$ cells $)$ in logarithmic growth were plated into each well of 96-well flat bottom, black sided culture plates and allowed to acclimate for $24 \mathrm{~h}$. Pc 4 was added at a final concentration of $1 \mathrm{nM}-10 \mu \mathrm{M}$ in medium containing $0.1 \%$ DMSO in every well under reduced lighting. Pc 4 was removed, cells were washed with PBS and the medium was replaced with complete RPMI after $48 \mathrm{~h}$. For the Pc 4 alone effects, the cells were allowed to grow for an additional $24 \mathrm{~h}$ in Pc 4 free medium before the addition of $50 \mu \mathrm{l}$ of $1 \mathrm{mg} / \mathrm{ml}$ MTT to each well. The plates for Pc 4 PDT were washed and medium was replaced with complete medium without Pc 4 . The laser component ( $670 \mathrm{~nm}$ with a fluence of $2.5 \mathrm{~J} / \mathrm{cm}^{2}$ as described above) of PDT was administered to the monolayers. Following laser exposure, the cells were incubated for an additional $24 \mathrm{~h}$ prior to the addition of $1 \mathrm{mg} / \mathrm{ml}$ MTT. After the addition of MTT, the cells were incubated for $4 \mathrm{~h}$ at which time medium containing MTT was removed from each well, $100 \mu \mathrm{L}$ DMSO was added and the plate was shaken for $5 \mathrm{~min}$. The absorbance at $570 \mathrm{~nm}$ was read on a Tecan Safire microplate reader (Tecan, San Jose, CA). Results were compared to wells containing vehicle-treated cells and expressed as \% inhibition. The $\mathrm{IC}_{50}$ was calculated using the Hill equation in the computer program ADAPT V from experiments with a minimum of triplicate samples at each concentration (D'Argenio, Schumitzky and Wang, 1997; https://bmsr.usc.edu/software/adapt/). The experiments were performed at least 3 times. 


\subsection{Cytotoxicity of Pc 4 and Pc 4 PDT in Spheroids}

Spheroids of CaSki or ME-180 cells $\left(1 \times 10^{4}\right.$ cells $)$ were prepared as described above. The spheroids were allowed to attach for $24 \mathrm{~h}$ and Pc 4 was added at a final concentration of $1 \mathrm{nM}-10 \mu \mathrm{M}$ in medium containing $0.1 \%$ DMSO in every well under reduced lighting. After $24 \mathrm{~h}$, the Pc 4 containing medium was removed; the spheroids were washed with PBS and new complete medium was added. The laser component $(670 \mathrm{~nm}$ with a fluence of $2.5 \mathrm{~J} / \mathrm{cm}^{2}$ as described above) of PDT was administered to the spheroids. After $24 \mathrm{~h}$, the spheroids were exposed to $1 \mathrm{mg} / \mathrm{ml} \mathrm{MTT}$ for $4 \mathrm{~h}$. The spheroids were then examined for the insoluble formazan using light microscopy and the percentage of cells surviving in each spheroid was estimated. The $\mathrm{IC}_{50}$ was calculated using the Hill equation in the computer program ADAPT V from experiments with a minimum of triplicate spheroids at each concentration (D’Argenio, Schumitzky and Wang, 1997; https://bmsr.usc.edu/software/adapt/). The experiments were performed at least three times.

\subsection{Pc 4 Uptake Studies}

Monolayers or spheroids of CaSki or ME-180 cells were prepared as described above. For monolayers, after $24 \mathrm{~h}, \mathrm{Pc} 4$ at $0.3 \mu \mathrm{M}$ was added in complete medium to each well; medium was removed at time points between $0-48 \mathrm{~h}$ and stored for analysis. After removal of medium, cells were washed with PBS and the wash removed. DMSO was then added to wells to solubilize the membranes and extract intracellular Pc 4 at time points between $0-48 \mathrm{~h}$. The medium and DMSO from wells was measured on the Tecan Saphire as fluorescence (ex: $350 \mathrm{~nm}$, em: $667 \mathrm{~nm}$ ) and values were back calculated from linear Pc 4 standard curves in medium and DMSO. Each time point was run in at least triplicate and with 3 separate assays. For spheroids, after 4 days when they had reached sizes of between 300 and 650 microns, kinetics of Pc 4 uptake in CaSki and ME-180 spheroids were determined. Pc 4 at $0.3 \mu \mathrm{M}$ was added to spheroid medium. Spheroids of uniform and equal sizes were chosen for imaging at ten $\mathrm{Z}$ positions between 0 and 150 microns from the top of the spheroids (step-size $=15$ or 25 microns). After the addition of Pc 4, confocal images were collected at intervals between 3 and $9 \mathrm{~h}$ over a $36 \mathrm{~h}$ period using an inverted Zeiss 510 Meta confocal microscope. The spheroids were kept at $37^{\circ} \mathrm{C}, 100 \%$ humidity and $5 \% \mathrm{CO}_{2}$ using a Tokai stage incubation chamber in the dark except for when confocal images were recorded.

\subsection{Intracellular Distribution of Pc 4}

CaSki and ME-180 cells were cultured on glass chamber-slides (Ibidi, $\mu$-Slide 8 Well, 80826). When cells were $50 \%$ confluent, adenovirus containing the gene coding for a cerulean-endoplasmatic reticulum (ER) marker fusion protein or a cerulean-mitochondria marker fusion protein was added to the cells at an MOI of 25; $48 \mathrm{~h}$ later, Pc 4 (at 0.3 $\mu \mathrm{M})$ was added and the cells were incubated for another $6 \mathrm{~h}$. To visualize lysosomes, LysoTracker Yellow protocol (LysoTracker ${ }^{\circledast}$ Yellow HCK-123, L-12491, ThermoFisher Scientific) was added $(75 \mathrm{nM})$ to the cell medium $3 \mathrm{~h}$ prior to incubation with Pc 4 . Af- 
ter washing with PBS, the cells were examined by confocal microscopy (Inverted Zeiss 510 Meta) and confocal micrographs were acquired.

\subsection{Intracellular Organelle Markers for Endoplasmic Reticulum and Mitochondria}

Expression plasmids containing ER or mitochondrial localized mCerulean3 were generously provided by Dr. Marcel Bruchez, Carnegie Mellon University [10]. The coding sequences from these plasmids were excised and inserted into a pENTR1A no $\operatorname{ccdB}$ Gateway shuttle vector using the following restriction enzymes: for the ER construct, BamHI/XbaI; for the mitochondria construct, BamHI/XhoI. Using Gateway LR Clonase II (Life Technologies, Waltham, MA), the resulting plasmids were recombined with the pAd/CMV/V5-DEST Gateway Vector to produce pAd/CMV-DEST-ER and pAd/ CMV-Dest-Mitochondria, respectively. These constructs were then utilized to produce adenovirus using the ViraPower ${ }^{\mathrm{Tm}}$ Adenoviral Gateway Expression Kit according to the manufacturer's recommendations (Life Technologies, Waltham, MA).

\subsection{Animals and Tumor Model}

Female C.B-17 SCID mice (specific pathogen-free, 4 - 6 weeks of age) were purchased from Charles River Laboratories (Wilmington, MA) and allowed 1 week to acclimate to the animal facilities at the University of Pittsburgh. Mice were handled in accordance with the Guide for the Care and Use of Laboratory Animals (National Research Council, 2012) and on a protocol approved by the University of Pittsburgh Institutional Animal Care and Use Committee. Two tumor models were utilized: intracervically implanted cells and subcutaneously implanted cells; both CaSki or ME-180 cells were used for each tumor model. A day before intracervical implantation of cervical cancer cells, the mice were anesthetized with isoflurane using a nose cone and their abdomens were shaved with any additional fur removed using a topical application of Nair ${ }^{\text {Tux }}$ for Men Cream. The abdomens were washed with warm water and the mice were allowed to recover from the anesthesia. On the day of surgical implantation, CaSki or ME-180 cells in logarithmic growth were harvested from culture. Mice to receive the cells were administered IV buprenorphine $(0.05 \mathrm{mg} / \mathrm{kg}) 2 \mathrm{~h}$ prior to surgery and the mice were anesthetized with IP Nembutal $(50 \mathrm{mg} / \mathrm{kg}$ ). Under anesthesia, the shaved site was cleaned with $70 \%$ ethanol followed by betadine scrub. Aseptic technique was used throughout the procedure. The skin over the linea alba was cut to create a longitudinal incision of approximately $1.5 \mathrm{~cm}$. Using mosquito hemostats the skin was retracted from the underlying muscle. A longitudinal incision of approximately $1 \mathrm{~cm}$ was made in the abdominal musculature directly on the midline. Using a sterile saline soaked $2 \times 2$ gauze pad the urinary bladder was expressed and the inguinal fat pads were moved out of the abdomen onto a saline soaked sterile gauze. Using a small curved forceps, the bifurcated uterus was gently pulled upward to expose the cervix. Cells $\left(1 \times 10^{5}\right.$ cells in $10 \mu \mathrm{L}$ of 1:1: complete medium:matrigel) were implanted intracervically using a $27 \mathrm{~g}$ needle and 0.5 cc syringe. The injection was confirmed by the formation of a small weal at the site of 
injection. After injection the uterus, cervix, fat pads, and urinary bladder were returned to the peritoneal cavity. The peritoneum and musculature was sutured with dissolvable sutures ( 3 sutures using X-1, $22 \mathrm{~mm} \mathrm{1/2} \mathrm{cm}$ reverse cutting needle and 3 - 0 coated vicryl plus antibacterial sutures, Ethicon Inc. Cincinnati, $\mathrm{OH}$ ) and the skin was sealed with surgical staples that were removed on post-operative day $5-7$. Buprenorphine was administered twice daily for 2 days post-operatively for pain relief. Tumor volumes were estimated by palpation twice weekly beginning after staples were removed, and scored as +1 to +5 depending on the size of the tumors.

In the second model, CaSki or ME-180 cells were implanted subcutaneously on the right flank of mice $\left(1 \times 10^{6}\right.$ cells in $100 \mu$ of complete medium).

\subsection{Pc 4 in Plasma and Tissues by HPLC}

When the intracervical tumors reached a score of +1 to +4 by palpation, the mice were administered Pc 4 (2 mg/kg in 1:1:10: cremophor:ethanol:saline) intravenously via tail vein and one mouse in each group was euthanized with $\mathrm{CO}_{2}$ at each of the following times: 6, 24, 48 and $72 \mathrm{~h}$ after dosing. Blood was collected by cardiac puncture and the select tissues (tumor, uterus, liver, kidneys, lungs, skeletal muscle, fat, spleen, colon) were removed, weighed and frozen in liquid nitrogen. The blood was centrifuged at $12,000 \times \mathrm{g}$ for $4 \mathrm{~min}$ at which point the plasma was separated from the RBCs, was transferred to cryovials, and stored, as the tissues were, at $-80^{\circ} \mathrm{C}$ until analyzed. Pc 4 concentrations were measured by HPLC as described previously [10] [15]. Tumors and tissues were homogenized in 3 volumes of PBS, and $200 \mu \mathrm{L}$ of each plasma sample or tissue homogenate was transferred to a separate tube containing $10 \mu \mathrm{L}$ of $10 \mathrm{mg} / \mathrm{mL}$ of Nile blue (internal standard). Samples were processed. Pc 4 standards (0.03, 0.1, 0.3, 1 , $3,10,30 \mu \mathrm{M}$ ) were prepared in tumor homogenate or plasma from untreated mice. The Beckman HPLC Programmable Gradient System (BeckmanCoulter, Fullerton, CA) consisted of a model 508 autosampler, a model 128 gradient solvent delivery module, and a model 166 UV detector. Compounds were separated on a IBondapak C18 column (10 $\mu \mathrm{m}, 3.9 \mu \mathrm{m}, 300 \mathrm{~mm}$, Waters Corp., Milford, MA) fitted with a Brownlee C18 guard column (Perkin-Elmer, Boston, MA). The isocratic mobile phase, consisting of methanol:dH2O:glacial acetic acid (80:20:1, vol/vol/vol), was pumped at $1 \mathrm{~mL} / \mathrm{min})$. The column eluent was monitored at $658 \mathrm{~nm}$. Under the above conditions, the retention times of Pc 4 and Nile blue were 4.5 and 5.3 min, respectively. Recovery was $81 \%$. The coefficient of variation was $<15 \%$ at low and medium high concentrations. Standard curves of Pc 4 were constructed by plotting the Pc 4 to internal standard area ratio versus the known concentration of Pc 4 in each sample. Standard curves were fit by linear regression and followed by back calculation of concentrations. Concentrations in unknown samples were calculated by comparison with the appropriate standard curve.

\subsection{PDT in Vivo}

Five SCID mice bearing ME-180 cells implanted intracervically were used for intravaginal PDT. Additionally, one SCID mouse bearing CaSki cells and one SCID mouse 
bearing ME-180 cells implanted subcutaneously were also used. When the intracervical tumors reached an estimated $100 \mathrm{~mm}^{3}$ based on palpation, the mice were administered Pc 4 at $2 \mathrm{mg} / \mathrm{kg} \mathrm{IV}$. Two days later, the mice were anesthetized with $50 \mathrm{mg} / \mathrm{kg}$ sodium pentobarbital. The mice were placed in the supine position on a platform and gently restrained so that the laser could be positioned intravaginally. The tumors were irradiated through a microlens diffuser fiber (P/N5470RevD; 400 micron core, Pioneer Optics Co., Bloomfield, CT) on a diode laser (HPD $670 \mathrm{~nm}$ laser, 7404-D-EXT; High Power Devices, Inc., New Brunswick, NJ) at $670 \mathrm{nM}$. The microfiber was inserted intravaginally approximately $0.4 \mathrm{~cm}$, this would ensure the fiber would be approximately $0.6 \mathrm{~cm}$ away from the vaginal apex, yielding a laser radius of $0.225 \mathrm{~cm}$ at the depth of the cervix and tumor. This laser radius was chosen to encompass the entire tumor, while decreasing exposure of normal tissues to PDT. The laser was calibrated using a power meter (PM100; Thorlabs, Newton, NJ). Irradiation was initially at a fluence of $150 \mathrm{~J} / \mathrm{cm}^{2}$ for two mice with intracervical tumors [15]. Secondary to toxicity, fluence was decreased to $75 \mathrm{~J} / \mathrm{cm}^{2}$ for 3 mice with intracervical tumors. The fluence was adjusted, and the time was kept constant at $4 \mathrm{~min}$, so the laser power was reduced appropriately from 100 to $50 \mathrm{~mW}\left(\mathrm{t}=\right.$ Fluence $\times\left(\pi \times\right.$ radius $\left.^{2}\right) /$ Power $)$. The subcutaneous tumors (diameter 1.25 $\mathrm{cm}$ ) were irradiated at a fluence of $150 \mathrm{~J} / \mathrm{cm}^{2}$ with a split microfiber for two mice for approximately $16 \mathrm{~min}\left(\mathrm{t}=\right.$ Fluence $\times\left(\pi \times\right.$ radius $\left.^{2}\right) /$ Power $)$ [15]. The mice were followed for recovery from anesthesia and twice daily after PDT. The fluence was decreased to 75 $\mathrm{J} / \mathrm{cm}^{2}$ and this fluence was used for irradiation of additional mice with intracervical xenografts and also for subcutaneous xenografts. The laser light was split into two beams with equal power by a bifurcated optical fiber assembly (Ocean Optics, Dunedin, FL) and delivered via two microlens fibers [16]. For the intracervical studies, the mice were administered $2 \mathrm{mg} / \mathrm{kg}$ Pc $448 \mathrm{~h}$ prior to irradiation and were restrained on their backs such that the laser was positioned to focus on the abdominal skin, on the tumor while reducing exposure to the gastrointestinal tract and liver. For the subcutaneous xenografts, mice were administered $2 \mathrm{mg} / \mathrm{kg}$ Pc $448 \mathrm{~h}$ prior to irradiation and were restrained on their left sides such that the laser was positioned to focus on the skin overlying their flanks.

Additional mice with either CaSki or ME-180 intracervical xenografts were imaged by PET CT every two weeks for three observations to measure the intracervical tumor spread. Mice were injected via tail vein with $1000 \mu \mathrm{Ci}{ }^{18} \mathrm{~F}$-fluoro deoxyglucose $\left({ }^{18} \mathrm{~F}\right.$-FDG, IBA Molecular, Morgantown WV) in saline and anesthetized with $1.5 \%$ isoflurane over $2 \mathrm{~L} /$ min oxygen and imaged at $2 \mathrm{~h}$ post-injection of ${ }^{18} \mathrm{~F}-\mathrm{FDG}$ in a Siemens Inveon multimodality PET/CT scanner. Animals were placed in a Trendelenberg position in the PET scanner to clear intestines from the pelvic area in order to aid in visualization of the cervix and their urinary bladders were expressed just prior to imaging. PET imaging consisted of a 5 min acquisition time for ${ }^{18} \mathrm{~F}$-FDG followed by a low magnification CT (120 projections, $4 \times 4$ binning, $80 \mathrm{kV} / 500 \mathrm{uA}$ with a $145 \mathrm{~ms}$ exposure) for anatomical reference of the PET signal. For ROI analysis, 2D FBP PET reconstruction was used and CT reconstruction was run with binning of two and downsampling of two with Sie- 
mens' Healthcare's Feldkamp reconstruction algorithm.

\section{Results}

\subsection{Growth and Cytotoxicity of Pc 4 and Pc 4 PDT in Monolayers}

When CaSki cells and ME-180 cells were grown as monolayers, their doubling times were 56 and 25 h respectively (data not shown). Pc 4, added under reduced lighting was relatively non-toxic and its $\mathrm{IC}_{50}$ in CaSki cells after $48 \mathrm{~h}$ of exposure was $7.6 \mu \mathrm{M}$, while after Pc 4 PDT, the $\mathrm{IC}_{50}$ was $0.016 \mu \mathrm{M}$ (Figure 2(a)). ME- 180 cells were less sensitive to Pc 4 and the $\mathrm{IC}_{50}$ for Pc 4 alone was $>10 \mu \mathrm{M}$. Higher concentrations of Pc 4 could not be evaluated because at higher concentrations the Pc 4 came out of solution in the medium. For ME-180 Pc 4 PDT, the $\mathrm{IC}_{50}$ was similar to that of the CaSki cells, $0.026 \mu \mathrm{M}$ (Figure 2(b)).
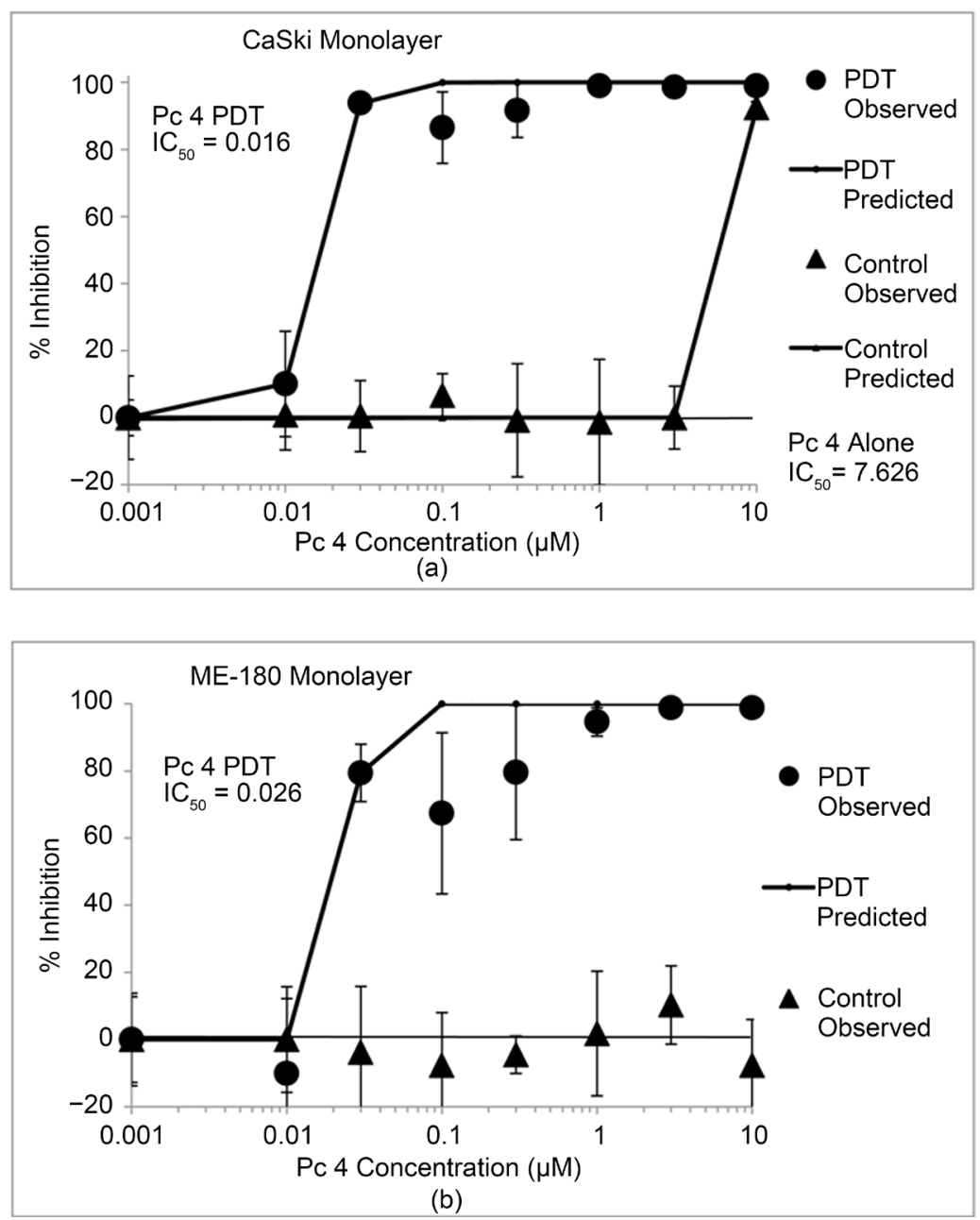

Figure 2. Cytotoxicity of Pc 4 and Pc 4 PDT in CaSki and ME-180 human cervical cancer cells grown as monolayers. (a): CaSki cells. (b): ME-180 cells (The cells were plated at $1 \times 10^{4}$ cells per well on 96-well black walled culture plates and the cells were allowed $24 \mathrm{~h}$ to attach. Pc 4 was then added in triplicate wells at concentrations between 0.001 and $10 \mu \mathrm{M}$. The MTT assays were conducted as described in the Methods. The results shown are representative of at least triplicate experiments performed on both cell lines). 


\subsection{Cytotoxicity of Pc 4 and Pc 4 PDT in Spheroids}

When CaSki cells and ME-180 cells were grown as spheroids, Pc 4 by itself was relatively non-toxic and its $\mathrm{IC}_{50}$ for each cell line could not be calculated using concentrations up to $10 \mu \mathrm{M}$ (Figures 3(a) and Figures 3(b)). For Pc 4 PDT, the $\mathrm{IC}_{50}$ in CaSki spheroids was much higher than had been observed in the CaSki cells grown as monolayers, 0.26 vs. $0.016 \mu \mathrm{M}$ (Figure $3(\mathrm{a})$ ). In the case of ME-180 spheroids, the $\mathrm{IC}_{50}$ was no higher than that of Pc 4 PDT for cells grown as monolayers $(0.011$ vs. $0.026 \mu \mathrm{M})$. This difference in response to Pc 4 PDT between cell types in response may be due to the structure of the spheroids; the ME-180 spheroids are much less tightly packed as is seen in Figure 3. The phase contrast images of insoluble formazan within the CaSki and ME-180 spheroids exposed to Pc 4 alone or after Pc 4 PDT are shown in Figure 3 (c) and Figure 3(d). Because we could not extract the insoluble formazan from the spheroids using DMSO and a number of other solvents, we sectioned the spheroids at their largest diameter $(\sim 300 \mu \mathrm{m})$ to determine the depth of penetration of formazan and confirm that the viable spheroids contained formazan throughout. An ME-180 spheroid treated with Pc 4 only is shown in Figure 3(e). As expected, there were no formazan crystals formed in the Pc 4 PDT treated spheroids beyond $0.1 \mu \mathrm{M}$ Pc 4 in CaSki spheroids and beyond $0.01 \mu \mathrm{M}$ in ME-180 spheroids.

\subsection{Pc 4 Uptake in Monolayers}

To confirm the uptake of Pc 4 in the CaSki and ME-180 cells, we measured both the concentration of Pc 4 in the medium and in the cells over time when the cells were continuously exposed to a Pc 4 concentration of $0.3 \mu \mathrm{M}$. As is apparent in Figure 4(a) and Figure 4(b), Pc 4 concentrations within the medium for both cell lines decreased with time, while the concentration of Pc 4 within the cells increased with time. By $6 \mathrm{~h}$ after addition of Pc 4 to the medium, the accumulation within the cells slowed and by $48 \mathrm{~h}$ represented approximately only $25 \%$ of the initial concentration added to the medium.

\subsection{Pc 4 Uptake in Spheroids}

Pc 4 accumulated at a slower rate in these cervical cell lines when they were grown as spheroids on matrigel. The rate of accumulation into the spheroids is shown in Figure 4(c) and Figure 4(d), as fluorescence units (measured in confocal images taken at various times after addition of $0.3 \mu \mathrm{M}$ Pc 4 at a depth of $105 \mu \mathrm{m}$ into CaSki spheroids and a depth of $175 \mu \mathrm{m}$ into the ME-180 spheroids). Uptake in CaSki spheroids was linear between 6 and $24 \mathrm{~h}$, and then remained constant, while the uptake in the ME-180 spheroids continued to increase over the $35 \mathrm{~h}$ of exposure (Figure $4(\mathrm{e})$ ).

\subsection{Intracellular Localization of Pc 4 in CaSki and ME-180 cells}

Pc 4 was widely distributed within intracellular organelles with a similar distribution in both CaSki and ME-180 cells. Pc 4 could be found in the cytosol, lysosomes, endoplasmic reticulum and in the mitochondria of both cell lines (Figure 5). In CaSki cells, the lysosomes appeared to show the most overlap between Pc 4 and the marker, followed 
by the endoplasmic reticulum; the mitochondria appeared to have less overlap between Pc 4 and the organelle marker (Figure 5(a)). A similar distribution was observed in the ME-180 cells grown as monolayers, but with more overlap between the mitochondrial marker and Pc 4 (Figure 5(b)).

\subsection{Tumor Growth in Mice}

In the mice after cervical implantation of either $1 \times 10^{5}$ CaSki or ME-180 cells, the
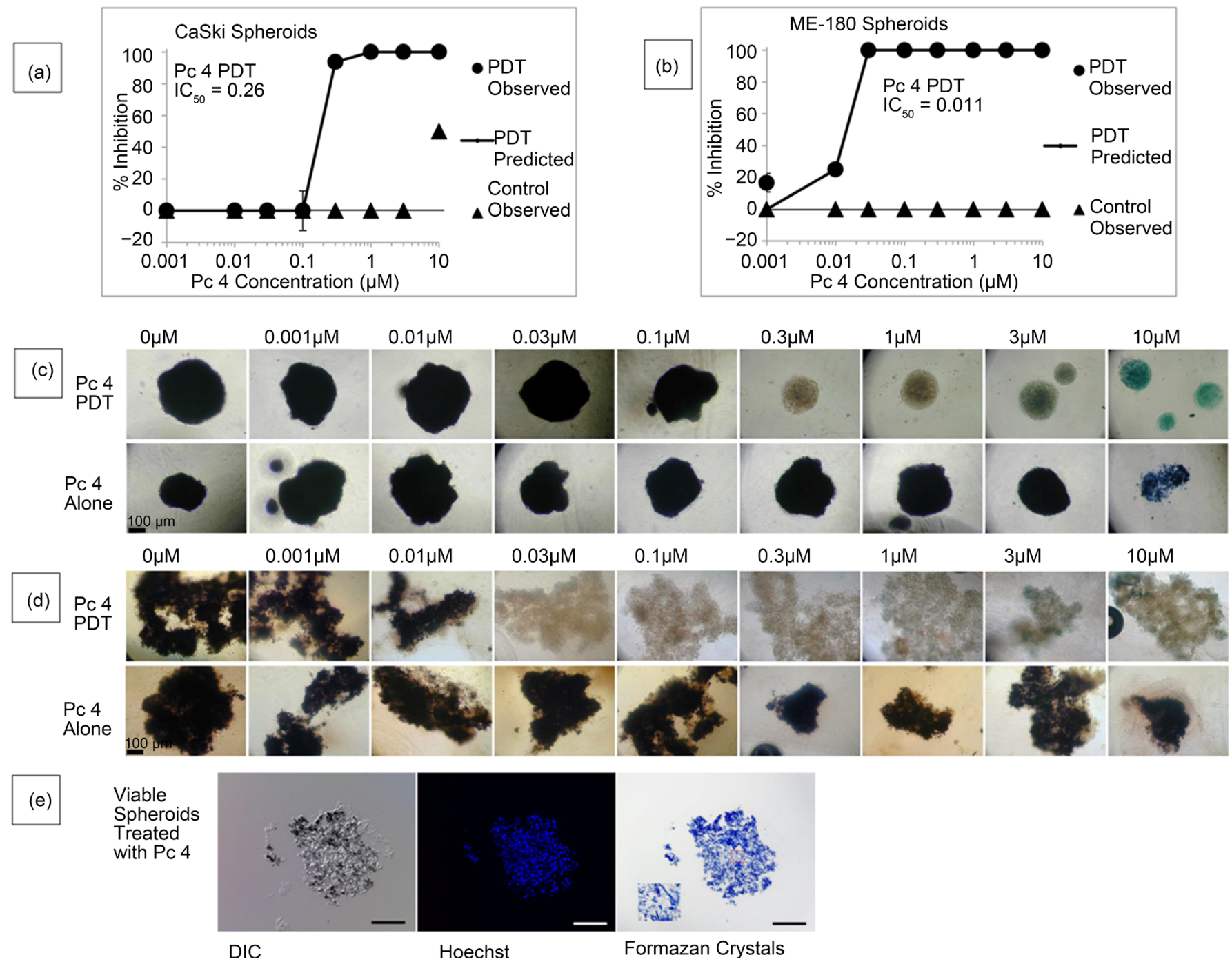

Figure 3. Cytotoxicity of Pc 4 and Pc 4 PDT in CaSki and ME-180 cells grown as spheroids (The cells were plated at $1 \times 10^{4}$ cells per hanging drop plate and $24 \mathrm{~h}$ later spun down on 96-well black walled culture plates over a layer of 1:1: Matrigel:complete medium $(50 \mu \mathrm{l}$ total) and the cells were allowed $24 \mathrm{~h}$ to attach. Pc 4 was then added in triplicate wells at concentrations between 0.001 and $10 \mu \mathrm{M}$. The MTT assays were conducted as described in the Methods. The results shown are representative of triplicate experiments performed on both cell lines. (a): CaSki spheroid cytotoxicity; (b): ME-180 spheroid cytotoxicity; (c): phase contrast of CaSki spheroids (400x) after MTT exposure; top row with Pc 4 PDT, bottom row with Pc 4 alone; (d): phase contrast of ME-180 spheroids (400×) after MTT exposure: top row with Pc 4 PDT, bottom row with Pc 4 alone; (e): panel 1 shows a ME-180 spheroid structure (differential contrast interference microscopy, DIC); panel 2 shows nuclei of the spheroids stained with Hoechst; panel 3 shows insoluable formazan crystals in the viable ME-180 spheroid (bright field microscopy). Insert in panel 3 is center square at $500 \times$ magnification). 

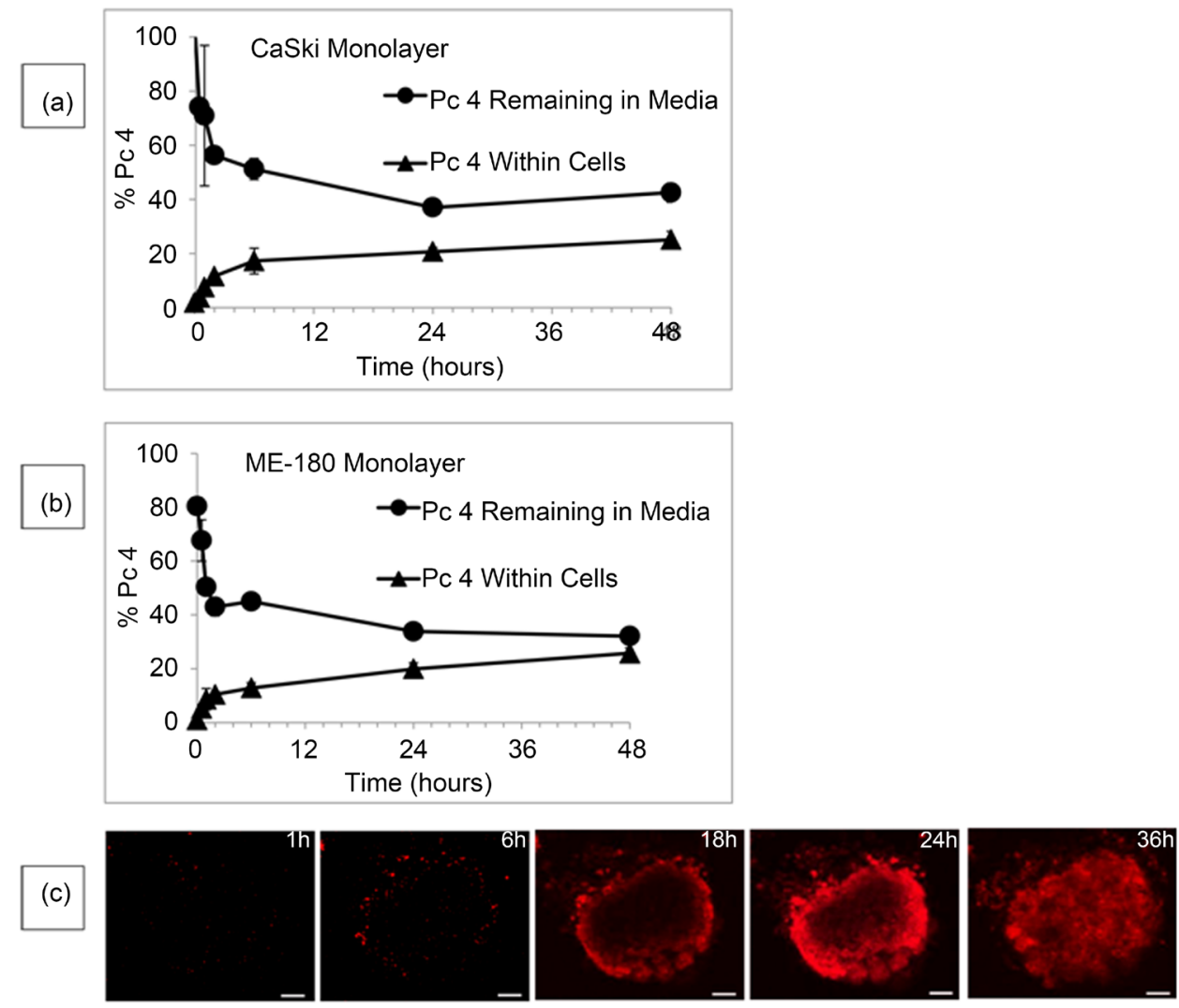

(d)
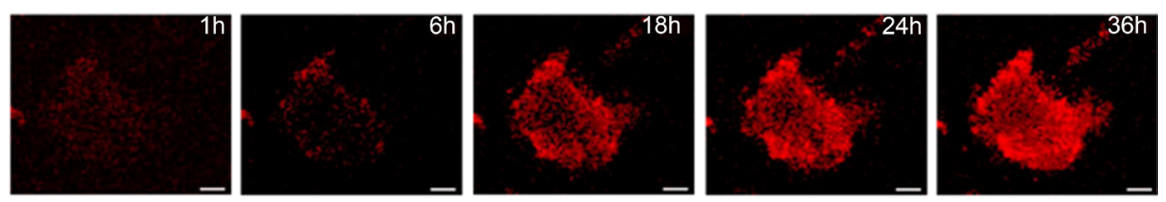

(e)

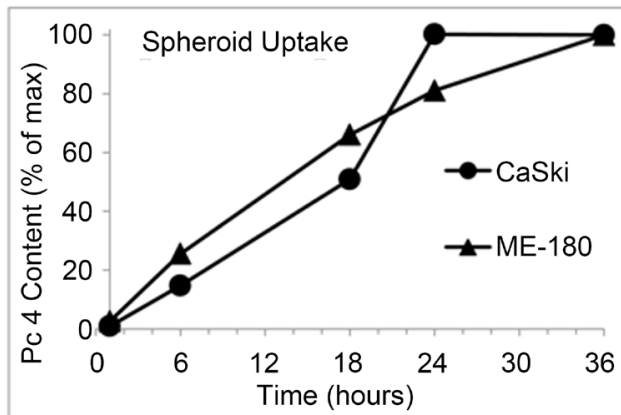

Figure 4. Uptake of Pc 4 in CaSki and ME-180 cells grown as both monolayers and spheroids (The cells were plated at $1 \times 10^{4}$ cells per well on 96 well black walled culture plates for monolayers and spheroids as described in the methods. For the monolayers, (a) and (c): medium containing Pc 4 at $0.3 \mu \mathrm{M}$ was harvested, cells washed, and intracellular Pc 4 extracted with DMSO at various time points between 0 and $48 \mathrm{~h}$. For the spheroids, (b) and (d): medium contained Pc 4 at $0.3 \mu \mathrm{M}$ and Pc 4 fluorescent units were calculated at a spheroid depth of 175 $\mu \mathrm{m}$ for the CaSki spheroids and at a depth of $105 \mu \mathrm{m}$ for the ME-180 spheroids. (e): Comparison of maximum Pc 4 fluorescence content of CaSki and ME-180 spheroids with time. The maximum content in each spheroid was achieved at $24 \mathrm{~h}$ (CaSki) or $35 \mathrm{~h}$ (ME-180) and the contents of Pc 4 fluorescence in earlier times were expressed as \% of this maximum for their respective cell line). 


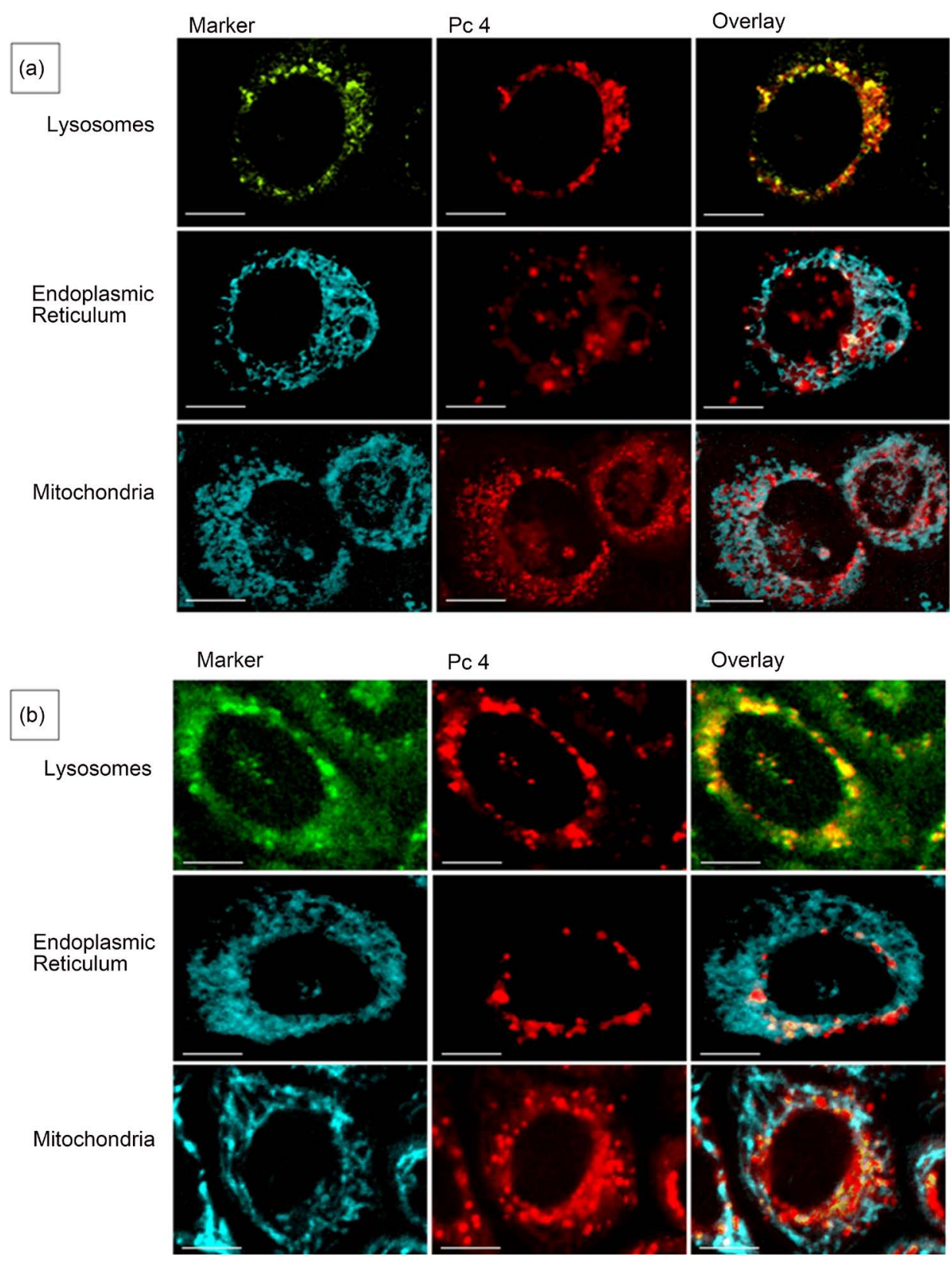

Figure 5. Intracellular distribution of Pc 4 in CaSki and ME-180 cells. The overlap of Pc 4 intracellularly with various organelle markers (lysosomes, endoplasmic reticulum, mitochondria) with confocal imaging. Pc 4 = red; LysoTracker = green; Cerulean-ER/Cerulean-Mitochondria = cyan; yellow color indicates co-localization of Pc 4 and the cell-organelle marker ( 1 bar = 10 microns). (a): CaSki cells. (b): ME-180 cells.

tumors initially grew as small nodules in the cervix. As the disease progressed, however, it spread up the uterine horns and tumors were also localized as nodules attached to the peritoneal wall or mesentery. Several nodules were located attached to mesentery in peritoneal cavity just below the xypoid process. Select mice also had more advanced disease: metastases in liver parenchyma; or pelvic side wall disease eventually encasing the ureters and leading to post-renal obstruction. The tumors did not appear to spread dis- 
tally to affect the vagina or anus. In the SCID mice, the tumor growth was much slower for the CaSki implanted cells than for the ME-180 implanted cells; CaSki tumors reached a volume of $500 \mathrm{~mm}^{3}$ by 8 - 9 weeks while the ME-180 tumors reached similar volumes in only 4 - 6 weeks as shown in Figure 7(a) and Figure 7(b).

\subsection{Pc 4 Concentration in Xenografts and Normal Tissues}

Four female SCID mice were implanted with CaSki cells and five with ME-180 cells subcutaneously on the right flank. One mouse bearing each xenograft was euthanized at 6, 24, 48 and $72 \mathrm{~h}$ after IV administration of Pc 4 at $2 \mathrm{mg} / \mathrm{kg}$. One mouse bearing an ME-180 xenograft served as control. As is apparent in Table 1, the tissue weights were similar between the mice, however the tumor weights were variable between mice receiving the same tumor cell line. ME-180 tumors varied between $0.059 \mathrm{~g}$ and $1.6 \mathrm{~g}$, while the CaSki tumors were slower growing and ranged between $0.09 \mathrm{~g}$ and $0.5 \mathrm{~g}$.

The concentrations of Pc 4 in the tissues are shown in Figure 6. The highest concentrations are present in liver, kidneys and lungs, while skeletal muscle concentrations are in the same concentration range as the tumors. The ME- 180 tumor Pc 4 concentrations decreased from $0.9 \mu \mathrm{M}$ at $6 \mathrm{~h}$ to $0.56 \mu \mathrm{M}$ at $48 \mathrm{~h}$, while in the CaSki xenografts, the concentration of Pc 4 rose between 6 and $24 \mathrm{~h}$, and then remained relatively constant between 24 and $72 \mathrm{~h}$. Plasma concentrations are not detectable after $48 \mathrm{~h}$ and are at

Table 1. Tissue weights for determination of Pc 4 concentrations in tissues of mice bearing xenografts following IV administration of Pc 4 at $2 \mathrm{mg} / \mathrm{kg}$.

\begin{tabular}{|c|c|c|c|c|c|c|c|c|c|c|}
\hline \multicolumn{11}{|c|}{ (a) $\mathrm{ME}-180$} \\
\hline & & \multicolumn{9}{|c|}{ Tissue weights (g) } \\
\hline $\begin{array}{c}\text { Mouse }^{1} \\
\text { time }\end{array}$ & Body weight (g) & Liver & Kidneys & Spleen & Lungs & Sk muscle & Fat & Uterus & $\begin{array}{c}\text { Cervical } \\
\text { tumor }\end{array}$ & Colon \\
\hline $6 \mathrm{~h}$ & 19.93 & 0.89 & 0.339 & 0.07 & 0.152 & 0.415 & 0.058 & 0.235 & 1.641 & 0.115 \\
\hline $24 \mathrm{~h}$ & 22.83 & 1.041 & 0.297 & 0.051 & 0.192 & 0.324 & 0.132 & 0.151 & 0.146 & 0.209 \\
\hline $48 \mathrm{~h}$ & 21.21 & 1.15 & 0.272 & 0.072 & 0.208 & 0.304 & 0.122 & 0.106 & 0.67 & 0.160 \\
\hline $72 \mathrm{~h}$ & 19.26 & 0.864 & 0.253 & 0.054 & 0.181 & 0.312 & 0.163 & 0.08 & 0.546 & 0.14 \\
\hline Predose & 23.01 & 1.141 & 0.287 & 0.056 & 0.187 & 0.404 & $\mathrm{NS}^{2}$ & 0.288 & 0.056 & 0.246 \\
\hline \multicolumn{11}{|c|}{ (b) $\mathrm{CaSki}$} \\
\hline & & \multicolumn{9}{|c|}{ Tissue weights (g) } \\
\hline $\begin{array}{c}\text { Mouse }^{3} \\
\text { time }\end{array}$ & Body weight (g) & Liver & Kidneys & Spleen & Lungs & Sk muscle & Fat & Uterus & $\begin{array}{c}\text { Cervical } \\
\text { tumor }\end{array}$ & Colon \\
\hline $6 \mathrm{~h}$ & 22.868 & 1.127 & 0.303 & 0.097 & 0.151 & 0.380 & 0.057 & 0.576 & 0.322 & 0.194 \\
\hline $24 \mathrm{~h}$ & 23.421 & 1.047 & 0.294 & 0.040 & 0.17 & 0.353 & 0.276 & 0.124 & 0.087 & 0.211 \\
\hline $48 \mathrm{~h}$ & 21.166 & 0.979 & 0.27 & 0.041 & 0.182 & 0.323 & 0.195 & 0.092 & 0.091 & 0.166 \\
\hline $72 \mathrm{~h}$ & 22.675 & 1.062 & 0.294 & 0.056 & 0.188 & 0.309 & 0.14 & 0.148 & 0.521 & 0.152 \\
\hline
\end{tabular}

${ }^{1}$ Mice were implanted with ME- 180 cells $\left(1 \times 10^{5}\right.$ cells/mouse intracervically) 7 weeks prior to Pc 4 ( $\left.2 \mathrm{mg} / \mathrm{kg} \mathrm{IV}\right)$. Mice were euthanized at the times after Pc 4 administration indicated above; ${ }^{2} \mathrm{NS}$ is no sample; ${ }^{3}$ Mice were implanted with CaSki cells $\left(1 \times 10^{5}\right.$ cells/mouse intracervically) 10 weeks prior to Pc $4(2 \mathrm{mg} / \mathrm{kg} \mathrm{IV})$. Mice were euthanized at the times after Pc 4 administration indicated above. 


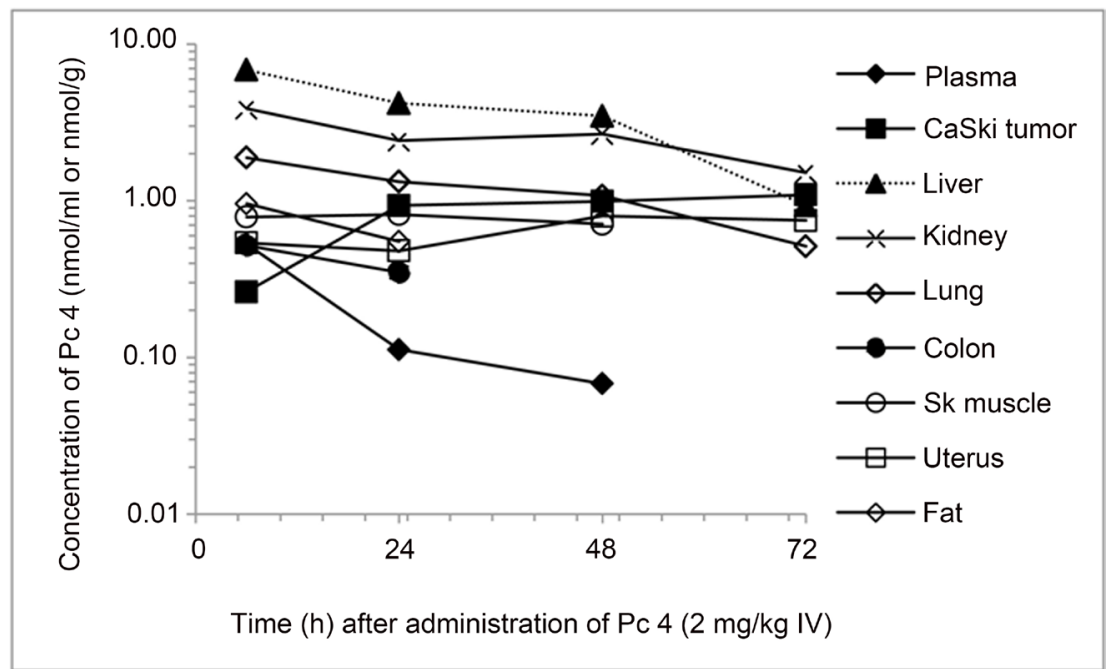

(a)

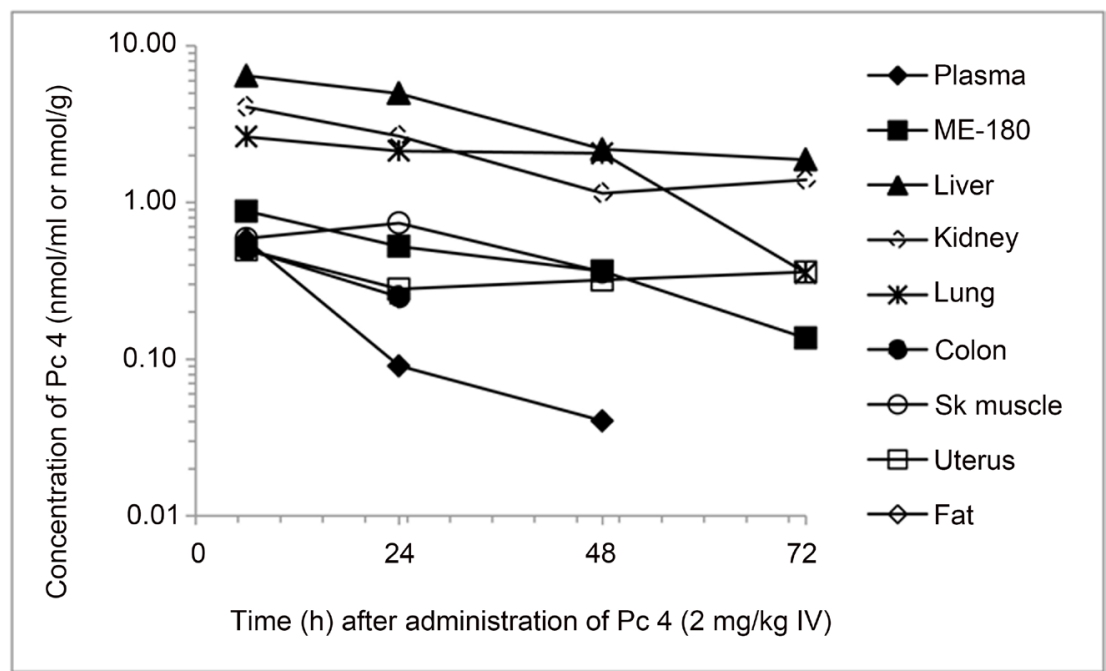

(b)

Figure 6. Concentrations of Pc 4 in tissues of mice bearing either CaSki or ME-180 xenografts. (Pc 4 concentrations as measured by HPLC were expressed as $\mu \mathrm{M}$ (nmol/g of tissue or $\mathrm{nmol} / \mathrm{ml}$ plasma). Individual mice were euthanized at each time point. (a): CaSki xenografts. (b): ME-180 xenografts.).

least a log lower than tumor concentrations. Intestinal concentrations (after removal of feces and PBS wash) and fat concentrations of Pc 4 are not detectable beyond $24 \mathrm{~h}$. The concentrations of Pc 4 in the uterus and in the cervical tumors were similar. Pc 4 distributes widely to tissues and is retained in the cervical tumors as well as in the uterus of the mice, but not at concentrations higher than the well perfused tissues of liver, kidneys and lungs.

\subsection{Pc 4 PDT in Vivo}

Five mice with intracervical ME-180 xenografts were treated with intravaginal irradiation of the cervical tumors. Two mice were irradiated at $150 \mathrm{~J} / \mathrm{cm}^{2}$ and three were irra- 
diated at $75 \mathrm{~J} / \mathrm{cm}^{2}$. All recovered from treatment and anesthesia within $1-2 \mathrm{~h}$ and appeared active. Of the two mice who received Pc 4 PDT with a fluence of $150 \mathrm{~J} / \mathrm{cm}^{2}$, one died five days after Pc 4 PDT, and one became scruffy and lethargic two days after Pc 4 PDT administration and was euthanized. Two of the three mice with intracervical tumors treated with Pc 4 PDT at a fluence of $75 \mathrm{~J} / \mathrm{cm}^{2}$ were found dead in their cages three days post-Pc 4 PDT. The other mouse had tumor shrinkage based on palpation after intravaginal Pc 4 PDT but was euthanized over a month later secondary to regrowth of tumor over $2 \mathrm{~g}$ at time of necropsy. Upon necropsy of all four mice who died after Pc 4 PDT, the tumors were reduced in size and were necrotic, but the intestinal tract was transparent and contained dark clots which suggested damage to the intestinal mucosa when the microfiber irradiation traveled beyond the small cervical tumors. One of the two mice who underwent treatment of its subcutaneous tumor with Pc 4 PDT at $150 \mathrm{~J} / \mathrm{cm}^{2}$ was found dead five days post-Pc 4 PDT. Both subcutaneous tumors had decreased in size and were necrotic after Pc 4 PDT.

An additional eight mice total, four with intracervically implanted CaSki or ME-180 xenografts, and four with subcutaneously implanted CaSki or ME-180 xenografts underwent Pc 4 PDT. As shown in Figure 7(c) and Figure 7(d), mice bearing CaSki intracervically implanted xenografts and ME-180 subcutaneously implanted xenografts received Pc 4 PDT trandermally with a lower irradiation of $75 \mathrm{~J} / \mathrm{cm}^{2}$. Pc 4 PDT resulted in reduced tumor volume. The mice recovered after the irradiation and mice with CaSki intracervically implanted xenografts were euthanized nine days later to accurately measure the reduction in tumor volume, as presented in Figure 7 (c). The mice with ME-180 subcutaneously implanted xenografts were followed for tumor regrowth until 70 days after initial implantation. Pc 4 PDT was more effective in the subcutaneously implanted xenografts and regrowth of the tumors did not occur until two weeks after treatment, as presented in Figure 7(d). The response to Pc 4 PDT of the ME-180 intracervically implanted xenografts was similar to the response of the CaSki intracervically implanted xenografts. Likewise, the response to Pc 4 PDT of the CaSki subcutaneously implanted xenografts was similar to the response of the ME-180 subcutaneously implanted xenografts (data not shown).

\section{Discussion}

In this study we have evaluated the use of a second generation phototherapeutic in the treatment of cervical cancer. For both the in vitro and in vivo studies presented here, we chose cell lines that would represent the HPV status of most cervical cancers. Both CaSki and ME-180 uterine cervical cancer cell lines are epithelial in origin and were derived from patients infected with high risk HPV. CaSki cells were derived from a 40 years old Caucasian woman from a small intestinal metastasis and had an integrated human papillomavirus type 16 genome (HPV-16, about 600 copies per cell) as well as sequences related to HPV-18. ME-180 cells were derived from a 66 years old Caucasian women from a metastatic site in the omentum and contain HPV DNA with greater homology to HPV-39 than HPV-18. These cell lines were chosen because they contain 
(a) Growth of CaSki Tumor Intracervically

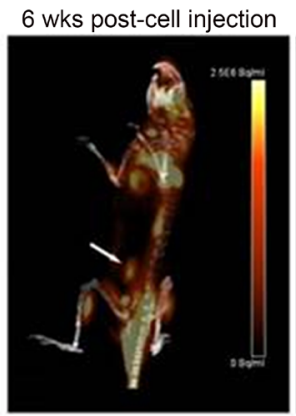

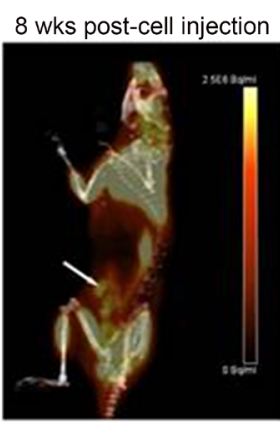

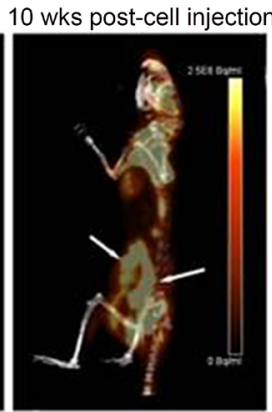

(b) Growth of ME-180 Tumor Intracervically

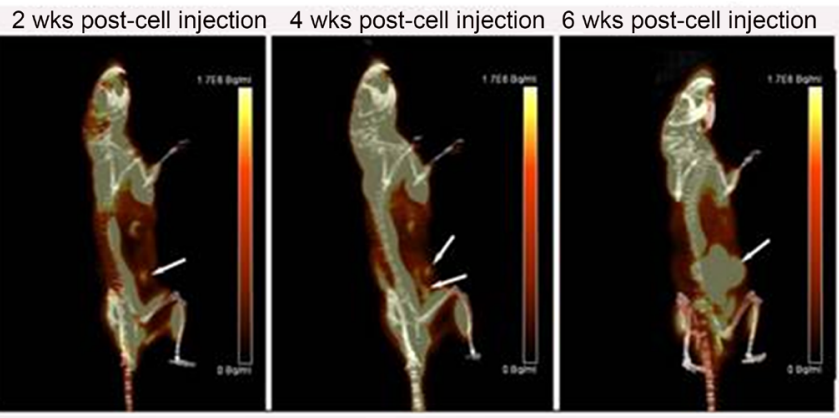

(c)

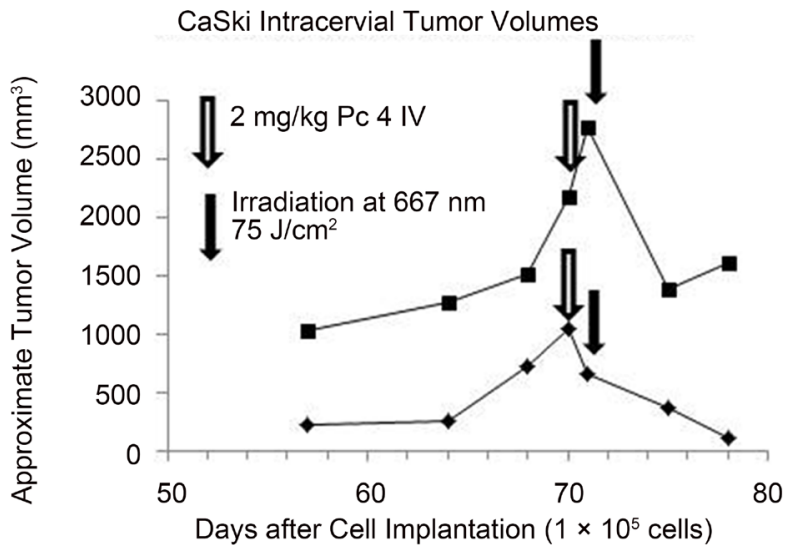

(d)

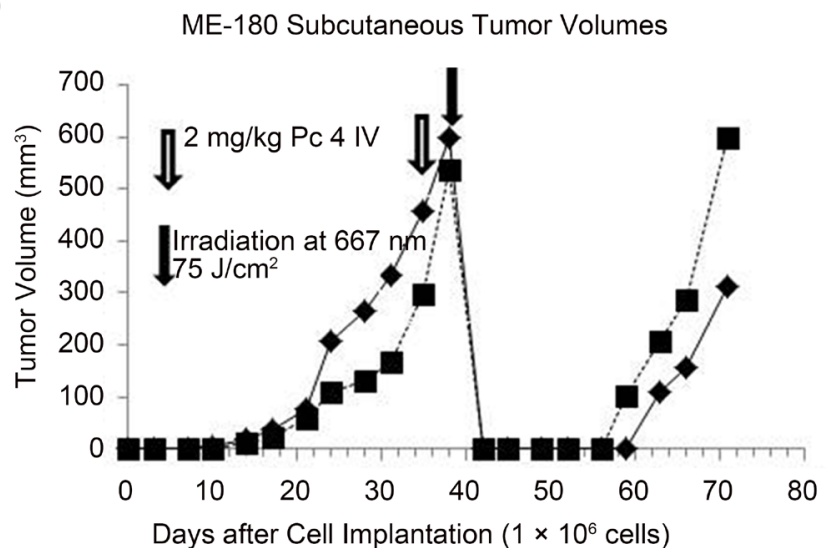

Figure 7. In vivo growth of intracervically implanted CaSki and ME-180 xenografts, and Pc 4 PDT response of xenografts, implanted both intracervically and subcutaneously. (a): Growth of CaSki xenografts in mice imaged by PET CT. (b): Growth of ME-180 xenografts in mice imaged by PET CT. The images of the mice were obtained at the times indicated after intracervical implantation of the cells and $2 \mathrm{~h}$ after IV injection of ${ }^{18} \mathrm{~F}$-FDG. Arrows indicate the tumors. (c): Effect of Pc 4 PDT on CaSki intracervical xenografts. (d): Effect of Pc 4 PDT on ME-180 subcutaneous xenografts.

DNA of the high risk HPV types (HPV 16, 18 and 39) which are considered to be carcinogenic and are associated with the development of cervical cancer. HPV types 16 and 18 as well as 45, 31, 33, 52, 58, and 35 are associated with 95\% of squamous-cell carcinomas of the cervix [17]. Both CaSki and ME-180 cells grow well in culture both as monolayers and as spheroids.

In our studies, we compared the response to Pc 4 PDT between monolayers and spheroids grown on Matrigel. Spheroids appear to be more representative of tumors in their response to therapeutic agents [18]. Further, the cervical cancer spheroids were placed on a matrigel:complete medium: 1:1 (v/v) foundation because cervical cancer appears to spread by local invasion to adjacent tissue structures and spheroids grown on extracellular matrix appear to be more representative of tumors [10] [18]. Tumors are better represented by spheroids because: morphology and proliferation rates are different than in monolayers; there is more phenotypic heterogeneity; gene expression is altered compared to monolayers and gradients for nutrients, catabolites, oxygen; and drugs exist and there are 3D tensional forces between cells [19]. In the case of both the CaSki and ME-180 spheroids, between 200 and $1000 \mu \mathrm{m}$ in diameter, the growth rate 
was much slower than in the monolayers. Further, as expected, Pc 4 did not appear to be toxic to the CaSki or ME-180 spheroids and much higher concentrations of Pc 4 were required with the same laser dose to cause cytotoxicity in the tighter CaSki spheroids. The $\mathrm{IC}_{50}$ for CaSki spheroids was $0.26 \mu \mathrm{M}$ while the $\mathrm{IC}_{50}$ for the ME- 180 spheriods was $0.011 \mu \mathrm{M}$. This difference in response to Pc 4 PDT correlates with their 3D structures: the CaSki cells grown as spheroids were true spheres and very tightly compacted; the ME-180 spheroids were looser and grew in random 3D shapes. It was difficult to disrupt both types of spheroids with DMSO and other solvents; because of this, aqueous insoluble formazan crystals from the metabolism of MTT could not be completely extracted from CaSki nor ME-180 spheroids. The inability to extract the insoluble formazan crystals meant the assessment of the assays measuring cytotocity in the spheroids required microscopic imaging.

Because higher concentrations of Pc 4 were required for PDT to kill the spheroids, we investigated the intracellular concentrations of Pc 4 in the monolayers and spheroids. When the cells were grown as monolayers starting with $1 \times 10^{4}$ cells in $200 \mu \mathrm{l}$ of complete medium containing a concentration of $0.3 \mu \mathrm{M}$ Pc 4 , by $6 \mathrm{~h}$ the cells had taken up more than $20 \%$ of the Pc 4 introduced into the wells and the intracellular concentrations were at least 50-fold higher than the medium concentrations. As expected, the uptake into the spheroids was slower due to the diffusion gradients, and at a depth of 70 $\mu \mathrm{m}$ into the spheroids, penetration of Pc 4 throughout the spheroid was not complete until $24 \mathrm{~h}$ of exposure. As expected, at earlier times, only the outer layers of the spheroid contained significant Pc 4 fluorescence (Figure 4).

The intracellular distribution of Pc 4 within the cervical cancer cells was similar to what has been observed in other tumor cell lines [12] [13]. In both cervical cancer cell lines, Pc 4 was localized within the cytoplasm, lysosomes, endoplasmic reticulum and mitochondria. This wide intracellular distribution of Pc 4 allows for widespread damage throughout the cell when the laser is applied to activate Pc 4. Pc 4 PDT results in activation of many of the cell death pathways including apoptosis and necrosis as well as reactive oxygen species [20].

Prior to conducting PDT studies in mice, we needed to establish the tumor models and understand the tumor growth characteristics when the cells were injected intracervically. In the mice the tumors grew in the cervix and in the peritoneum near the opening of the fallopian tubes above one horn of the bifurcated uterus. Only in advanced disease were metastases detected within the liver. Most lesions remained within the peritoneal cavity and firmly attached to the peritoneal wall. Mice had as many as ten different tumor nodules in late stage disease, reflecting the metastatic nature of the tumor cell lines examined. The CaSki tumor xenografts grew more slowly within the peritoneum than did the ME-180 xenografts, in agreement with their doubling times when grown as monolayers. With intracervical implantation, the spread of these cells in SCID mice resembled the spread of human cervical squamous cell carcinomas in that it involved the paracervical and parauterine tissue. In advanced disease in mice it differed in that there was intraperitoneal spread. In humans cervical squamous carcinoma grows 
to involve the endometrium superiorly and the upper vagina inferiorly. Parametrial involvement results from extension through the cervical stroma. From the parametrium the tumor may extend laterally to the pelvic sidewall, anteriorly to the bladder base or posteriorly to the rectum. Squamous cell carcinoma also spreads to the endometrium, fallopian tubes, and ovaries [21] [22] [23]. Vascular and lymphatic invasion can occur leading to pelvic lymph node metastasis [23].

When Pc 4 concentration in xenografts and normal tissues was measured with time in the SCID mice bearing either CaSki or ME-180 xenografts, Pc 4 distributed rapidly to normal tissues with high perfusion rates, such as the liver, lungs and kidneys; these tissues also had the highest concentrations of Pc 4. At the earliest time point examined in this study, concentrations in these tissues were already at least a magnitude higher than plasma, and retained the highest concentrations out to the final observation time of $72 \mathrm{~h}$; plasma concentrations fell between 6 and $48 \mathrm{~h}$ and could not be detected at 72 h. Similarly, the concentrations in the colons and inguinal fat of the mice could not be detected beyond $24 \mathrm{~h}$. Uterus, skeletal muscle and tumor concentrations of Pc 4 were detected at $6 \mathrm{~h}$ and remained relatively constant at approximately 0.5 to $1 \mu \mathrm{M}$ throughout the $72 \mathrm{~h}$ time point. Because only a single mouse was used for each time point determination, the variability in the concentrations could not be determined. Nonetheless, this data is consistent with our previous observations of the concentrations of Pc 4 in normal CD2F1 female mice [10]. Based on the data presented here and our data from previous studies with other xenograft models in mice [15], we chose to apply the laser irradiation at $48 \mathrm{~h}$ after IV administration of Pc 4 at $2 \mathrm{mg} / \mathrm{kg}$.

Our attempt at laser irradiation through the vaginal opening to treat the intracervical lesions was not successful. Although the mice survived the initial irradiation and the tumor appeared to be killed, four of the five mice with intracervical tumors, and one of two mice with subcutaneous tumors, had to be euthanized or died between two and five days after irradiation. It was apparent on necropsy that the irradiation had affected the small intestines as they were transparent and filled with black clots suggesting severe damage to the mucosal lining. We had considered the emptying time of the gastrointestinal tract of mice, (estimated at $6 \mathrm{~h}$ in mice when the major route of elimination was through the feces [24]) and had demonstrated that Pc 4 concentrations could not be detected in the colonic tissue past $24 \mathrm{~h}$; we should have considered, however, the slow release and redistribution of Pc 4 from storage sites within other tissues. Most probably, Pc 4 was present in the contents of the gastrointestinal tract at high enough concentrations to result in injury and death of the mice when $75 \mathrm{~J} / \mathrm{cm}^{2}$ of irradiation at $670 \mathrm{~nm}$ was applied through the microfiber. In contrast, when the additional eight mice received Pc 4 PDT with transdermally applied laser irradiation, tumor volume was reduced and all mice survived. The delay in regrowth of xenografts suggests that additional irradiation could be applied at an interval of two weeks to prevent regrowth.

Pc 4 has advantages over a number of other sensitizers as it is a defined compound with known spectra, while the spectra of tissue synthesized porphyrins after application of ALA or its related compounds are not known. Photofrin, Porfimer sodium, is a mix- 
ture of compounds as well, and has been used to treat CIN. Japanese studies have shown that colposcopic-assisted cervical canal illumination after intravenous Photofrin administration can achieve a high CR (<94\%) [25]. A newer agent Radachlorin ${ }^{\oplus}$ has been shown to be an effective PDT agent against cervical cancer cells [26] [27], however, the cell line, TC-1, was derived from epithelial cells of the lungs of C57BL/6 mice and transformed by HPV-16 E6 and E7. Photochlor (HPPH), like Pc 4, is a second generation photosensitizer that is currently in clinical trials. Both Pc 4 and Photochlor are single compounds with absorption spectra in the high 600's, have good tissue distribution and have better pharmacokinetics than Photofrin, with shorter periods of photosensitivity when administered intravenously [28].

This is the first study to investigate PDT utilizing Pc 4 and its effects on cervical cancer cells both in vitro and in vivo. We have demonstrated in vitro that Pc 4 itself in relatively non-toxic and Pc 4 PDT is effective at killing cervical cancer cells grown as either spheroids or monolayers. We have demonstrated in vivo that intracervical tumors in mice became necrotic after Pc 4 PDT. Previous studies using PDT with other photosensitizers to treat CIN have had promising results [8] [29]. We are encouraged therefore by the possibility of continuing these studies further in animals and eventually to women for the treatment cervical neoplasia. We feel the most clinically relevant application of Pc 4 PDT may be in its topical application in the treatment of CIN where light can be specifically directed at localized cervical lesions. The fact that PDT used in the treatment of CIN could potentially avoid the morbidity associated with current excisional or ablative techniques makes Pc 4 PDT worth investigating further. Pharmacokinetic studies would need to be performed in patients to identify the optimal drug dose for treatment of invasive cervical carcinoma due to the proximity of the lesion to vital organs. In addition, the application and dose of light would have to be focused more directly within the cervical lesion, either by direct application or interstitial therapy.

\section{Acknowledgements}

Support provided by: Costwold Foundation Pharmacology Fellowship (EJC), UPCI In Vivo Imaging Grant (JTC, JLE), Cancer Center Core Grant P30-CA47904 (Cell and Tissue Imaging Facility, Cancer Pharmacokinetics and Pharmacodynamics Facility, and Animal Facility Cores), CTSI BaCCoR Pilot Program (JTC, JLE).

\section{References}

[1] Ferlay, J., Soerjomataram, I., Ervik, M., Dikshit, R., Eser, S., Mathers, C., Rebelo, M., Parkin, D.M., Forman, D. and Bray, F. (2013) GLOBOCAN 2012 v1.0, Cancer Incidence and Mortality Worldwide: IARC CancerBase No. 11. International Agency for Research on Cancer, Lyon. http://globocan.iarc.fr

[2] World Health Organization and Regional Office Africa (2015) Cervical Cancer. http://www.afro.who.int/en/cancer/cervical-cancer/2810-cervical-cancer.html

[3] American Cancer Society (2015) Cancer Facts and Figures. http://www.cancer.org/cancer/cervicalcancer/detailedguide/cervical-cancer-key-statistics

[4] Minig, L., Patrono, M.G., Romero, N., Moreno, J.F.R. and Garcia-Donas, J. (2014) Different 
Strategies of Treatment for Uterine Cervical Carcinoma Stage 1B2-IIB. World Journal of Clinical Oncology, 5, 86-92. https://doi.org/10.5306/wjco.v5.i2.86

[5] Hequet, D., Marchand, E., Place, V., Fourchotte, V., De La Rochefordière, A., Dridi, S., Coutant, C., Lecuru, F., Bats, A.S., Koskas, M., Bretel, J.J., Bricou, A., Delpech, Y. and Barranger, E. (2013) Evaluation and Impact of Residual Disease in Locally Advanced Cervical Cancer after Concurrent Chemoradiation Therapy: Results of a Multicenter Study. European Journal of Surgical Oncology, 39, 1428-1434.

https://doi.org/10.1016/j.ejso.2013.10.006

[6] Jancar, N., Rakar, S., Poljak, M., Fujs, K., Kocja, B.J. and Vrtacnik-Bokal, E. (2006) Efficiency of Three Surgical Procedures in Eliminating High-Risk Human Papilloma Virus Infection in Woman with Precancerous Cervical Lesions. European Journal of Gynaecological Oncology, 27, 239-242.

[7] Wilkinson, E.J. (2009) Women with Cervical Intraepithelial Neoplasia: Requirement for Active Long-Term Surveillance after Therapy. Journal of the National Cancer Institute, 101, 696-697. https://doi.org/10.1093/jnci/djp097

[8] Shishkova, N., Kuznetsova, O. and Berezov, T. (2012) Photodynamic Therapy for Gynecological Diseases and Breast Cancer. Cancer Biology and Medicine, 9, 9-17.

[9] Jakobsson, M. and Norwitz, E.R. (2015) Cervical Intraepithelial Neoplasia: Reproductive Effects of Treatment. http://www.uptodate.com/contents/cervical-intraepithelial-neoplasia-reproductive-effectsof-treatment?source=search_result\&search=Cervical+intraepithelial+neoplasia\%3A+Repro ductive+effects + of + treatment $\&$ selectedTitle $=4 \% 7 \mathrm{E} 150$

[10] Telmer, C.A., Verma, R., Teng, H., Andreko, S., Law, L. and Bruchez, M.P. (2015) Rapid, Specific, No-Wash, Far-Red Fluorogen Activation in Subcellular Compartments by Targeted Fluorogen Activating Proteins. ACS Chemical Biology, 10, 1239-1246. https://doi.org/10.1021/cb500957k

[11] Egorin, M.J., Zuhowski, E.G., Sentz, D.L., Dobson, J.M., Callery, P.S. and Eiseman, J.L. (1999) Plasma Pharmacokinetics and Tissue Distribution in CD2F1 Mice of Pc 4 (NSC 676418), a Silicone Phthalocyanine Photodynamic Sensitizing Agent. Cancer Chemotherapy and Pharmacology, 44, 283-294. https://doi.org/10.1007/s002800050979

[12] Lam, M., Hsia, A.H., Liu, Y., Guo, M., Swick, A.R., Berlin, J.C., McCormick, T.S., Kenney M.E., Oleinick, N.L., Cooper, K.D. and Baron, E.D. (2011) Successful Cutaneous Delivery of the Photosensitizer Silicon Phthalocyanine 4 for Photodynamic Therapy. Clinical and EXperimental Dermatology, 36, 645-651. https://doi.org/10.1111/j.1365-2230.2010.03989.x

[13] Oleinick, N., Morris, R.L. and Belichenko, I. (2002) The Role of Apoptosis in Response to Photodynamic Therapy: What, Where, Why, and How. Photochemical \& Photobiolological Sciences, 1, 1-21. https://doi.org/10.1039/b108586g

[14] Master, A., Malamas, A., Solanki, R., Clausen, D.M., Eiseman, J.L. and Sen Gupta, A. (2013) A Cell-Targeted Photodynamic Nanomedicine Strategy for Head and Neck Cancers. Molecular Pharmaceutics, 10, 1988-1997. https://doi.org/10.1021/mp400007k

[15] Bai, L., Guo, J., Bontempo, F.A. and Eiseman, J.L. (2009) The Relationship of Phthalocyanine 4 (Pc 4) Concentrations Measured Noninvasively to Outcome of Pc 4 Photodynamic Therapy in Mice. Photochemistry and Photobiology, 85, 1011-1019. https://doi.org/10.1111/j.1751-1097.2009.00542.x

[16] Baron, E.D., Malbasa, C.L., Santo-Domingo, D., Fu, P., Miller, J.D., Hanneman, K.K., Hsia, A.H., Oleinick, N.L., Colussi, V.C. and Cooper, K.D. (2010) Silicion Phthalocyanin (Pc 4) Photodynamic Therapy Is a Safe Modality for Cutaneous Neoplasms: Results of a Phase 1 Clinical Trial. Lasers in Surgery and Medicine, 42, 728-735. 
https://doi.org/10.1002/lsm.20984

[17] Muñoz, N., Bosch, F.X., de Sanjosé, S., Herrero, R., Castellsagué, X., Shah, K.V., Snijders, P.J. and Meijer, C.J. (2003) Epidemiologic Classification of Human Papillomavirus Types Associated with Cervical Cancer. New England Journal of Medicine, 348, 518-527. https://doi.org/10.1056/NEJMoa021641

[18] Hirschhaeuser, F., Menne, H., Dittfeld, C.C., West, J., Mueller-Klieser, W. and KunzSchughart, L.A. (2010) Multicellular Tumor Spheroids: An Underestimated Tool Is Catching up Again. Journal of Biotechnology, 148, 3-15. https://doi.org/10.1016/j.jbiotec.2010.01.012

[19] 3D Biomatrix, Inc. (2013) 5 Reasons Cancer Researchers Adopt 3D Cell Culture: A Review of Recent Literature. https://3dbiomatrix.com/wp-content/uploads/2013/10/5-Reasons-Cancer-Researchers-Ado pt-3D-Cell-Culture-White-Paper.pdf

[20] Mroz, P., Yaroslavsky, A., Kharkwal, G.B. and Hamblin, M.R. (2011) Cell Death Pathways in Photodynamic Therapy of Cancer. Cancers, 3, 2516-2539. https://doi.org/10.3390/cancers3022516

[21] Kanbour, A.I. and Stock, R.J. (1978) Squamous Cell Carcinoma in Situ of the Endometrium and Fallopian Tube as Superficial Extension of Invasive Cervical Carcinoma. Cancer, 42, 570-580. https://doi.org/10.1002/1097-0142(197808)42:2<570::AID-CNCR2820420225>3.0.CO;2-N

[22] Motoyama, T. and Wantanabe, H. (1988) Squamous Cell Carcinoma of the Cervix with Extensive Superficial Spreading to almost Whole Genital Tract and Associated with Endometrial Stromal Sarcoma. Acta Pathologica Japonica, 38, 1445-1452.

[23] Maniar, K.P. and Wei, J. (2009) Pathology of Cervical Carcinoma. http://www.glowm.com/section_view/heading/Pathology\%20of\%20Cervical\%20Carcinoma /item/230

[24] Padmanabhan, P., Grosse, J., Asad A.B., Radda, G.K. and Golay, X. (2013) Gastrointestinal Transit Measurements in Mice with ${ }^{99 \mathrm{~m}}$ Tc-DTPA-Labeled Activated Charcoal Using NanoSPECT-CT. EJNMMI Research, 3, 60. https://doi.org/10.1186/2191-219X-3-60

[25] Huang, Z. (2005) A Review of Progress in Clinical Photodynamic Therapy. Technology in Cancer Research and Treatment, 4, 283-293. https://doi.org/10.1177/153303460500400308

[26] Bae, S.M., Kim, Y.W., Lee J.M., Namkoong, S.E, Han, S.J., Kim, J.K., Lee, C.H., Chun, H.J., Jin, H.S. and Ahn, W.S. (2004) Photodynamic Effects of Radachlorin ${ }^{\circledR}$ on Cervical Cancer Cells. Cancer Research and Treatment, 36, 389-394. https://doi.org/10.4143/crt.2004.36.6.389

[27] Kim, Y.W., Bae, S.M., Battogtokh, G., Bang, H.J. and Ahn, W.S. (2012) Synergistic AntiTumor Effects of Combination of Photodynamic Therapy and Arsenic Compound in Cervical Cancer Cells: In Vivo and in Vitro Studies. PLoS ONE, 7, e38583. https://doi.org/10.1371/journal.pone.0038583

[28] Bellnier, D.A., Greco, W.R., Goewen, G.M., Nava, H., Oseroff, A.R. and Dougherty, T.J. (2006) Clinical Pharmacokinetics of the PDT Photosensitizers Porfimer Sodium (Photofrin), 2-[1-Hexyloxyethyl]-2-devinyl pyropheophorbide-a (Photochlor) and 5-ALA-Induced Protoporphyrin IX. Lasers in Surgery and Medicine, 38, 439-444. https://doi.org/10.1002/lsm.20340

[29] Choi, M.C., Jung, S.G., Park, H., Lee, S.Y., Lee, C., Hwang, Y.Y. and Kim S.J. (2013) Photodynamic Therapy for Management of Cervical Intraepithelial Neoplasia II and III in Young Patients and Obstetric Outcomes. Lasers in Surgery and Medicine, 45, 564-572. https://doi.org/10.1002/lsm.22187 
Submit or recommend next manuscript to SCIRP and we will provide best service for you:

Accepting pre-submission inquiries through Email, Facebook, LinkedIn, Twitter, etc. A wide selection of journals (inclusive of 9 subjects, more than 200 journals)

Providing 24-hour high-quality service

User-friendly online submission system

Fair and swift peer-review system

Efficient typesetting and proofreading procedure

Display of the result of downloads and visits, as well as the number of cited articles

Maximum dissemination of your research work

Submit your manuscript at: http://papersubmission.scirp.org/

Or contact abc@scirp.org 